\title{
Results of intraoperative mitomycin C application in dacryocystorhinostomy
}

\author{
Shu L Liao, Shine C S Kao, Jason H S Tseng, Muh S Chen, Ping K Hou
}

\begin{abstract}
Aims-To evaluate the long term results of intraoperative mitomycin $\mathrm{C}$ application in dacryocystorhinostomy (DCR) surgery compared with results of the conventional procedure.

Methods-In this prospective randomised controlled study, a total of 88 eyes diagnosed with acquired nasolacrimal duct obstruction were randomly divided into a conventional DCR group and a mitomycin C group in which mitomycin $C$ was used during DCR surgery. The surgical procedures in both groups were exactly the same, except that in the patients in the mitomycin $\mathbf{C}$ group, a piece of neurosurgical cottonoid soaked with $0.2 \mathrm{mg} / \mathrm{ml}$ mitomycin $\mathrm{C}$ was applied to the osteotomy site for 30 minutes. The results of the DCR surgeries were evaluated by objective findings such as irrigation and the height of tear meniscus and subjective symptoms by asking patients the condition of tearing improvement.
\end{abstract}

Results-Among the 44 eyes in the mitomycin C group, $95.5 \%$ of patients remained totally symptom free after 10 months of follow up; while in the conventional group, $70.5 \%$ of patients were reported to be symptom free and $18 \%$ of patients to have an improvement in their symptoms. There was a significant difference between these two groups. As far as objective findings were concerned, there were 41 eyes in the mitomycin $C$ group classified as having a normal and one eye with moderate tear meniscus level, compared with 32 eyes and seven eyes, respectively, in the conventional group. There was also a significant difference between these two groups. The non-patency rate in the mitomycin $\mathrm{C}$ group is $4.5 \%$ compared with $11.4 \%$ in the conventional group. There were no complications such as abnormal nasal bleeding, mucosal necrosis, or infection except one patient with delayed wound healing.

Conclusions-Intraoperative mitomycin $C$ application is effective in increasing the success rate of DCR surgery in standard nasolacrimal duct obstruction, and no significant complications resulted from its use.

(Br F Ophthalmol 2000;84:903-906)

Most ophthalmic surgeons accept dacryocystorhinostomy (DCR) as a highly successful procedure in managing epiphora due to nasolacrimal duct obstruction. From previous studies, it appears that the success rate for this procedure is about $90 \% .^{1-3}$ The two most frequent causes of DCR failure are obstruction of the common canaliculus and closure of the osteotomy site. ${ }^{4-6}$ Thus, if we can inhibit fibrous tissue growth and scarring by applying antiproliferative agents over the anastomosed flaps and osteostomy site, the failure rate may be decreased.

Mitomycin C, an antiproliferative agent, has been widely used in pterygium excision and trabeculectomy with favourable results. ${ }^{78}$ Our previous study also demonstrated that DCR with intraoperative mitomycin $\mathrm{C}$ application can maintain larger osteotomy size than that of the conventional procedure. ${ }^{9}$ In this paper, we evaluate the long term success rate of DCR surgery with intraoperative mitomycin $\mathrm{C}$ soaking.

Subjects and methods

During 1995 to 1998,88 patients with a diagnosis of primary acquired nasolacrimal duct obstruction were randomly assigned into mitomycin C and conventional DCR groups. All the procedures were performed by two surgeons (SCSK and SLL). The mean age of the conventional group was 57.4 (SD 10.2) years, and that of the mitomycin C group was 57.9 (7.4) years. All the patients had been followed up for more than 10 months for the evaluation of objective findings as well as subjective symptoms.

The standard surgical techniques of an external DCR were used in all patients of both groups. Local infiltrative anaesthesia, consisting of $\%$ lignocaine (lidocaine) and 1:100 000 adrenaline (epinephrine), was administered in the region of the medial canthus and lower lid. The nasal mucosa was anaesthetised and vasconstricted with pledgets saturated with a mixture of $5 \%$ cocaine and 1:100 000 adrenaline. A skin incision was performed and blunt dissection to the periosteum overlying the anterior lacrimal crest was undertaken. The periosteum was then incised and elevated off the lacrimal sac fossa. The osteotomy was created over the lacrimal fossa with an electric drill. The lacrimal sac was opened in a longitudinal fashion to form anterior and posterior flaps. The nasal mucosa was cut in a similar fashion to the lacrimal sac. Then, the posterior nasal and lacrimal sac flaps were joined with 5-0 Vicryl suture. A silicone tube was used to intubate the lacrimal system and followed by being tied together with a 4-0 silk suture. In the mitomycin C group, once the silicone tube was in place, a piece of neurosurgical cottonoid attached with a long thread, saturated with 0.2 
$\mathrm{mg} / \mathrm{ml}$ mitomycin $\mathrm{C}$ was placed over the anastomosed posterior flaps and osteotomy site with the long thread passing out through the nostril, and was then removed transnasally after an application time of 30 minutes. The anterior nasal and lacrimal sac flaps were closed with additional 5-0 Vicryl sutures, as were the periosteum and orbicularis muscle in separate layers. The skin incision was sutured with a running 6-0 nylon suture. The mitomycin C saturated cottonoid was removed transnasally after a 30 minute soak by pulling the long thread out from the nostril. In the conventional group, the same procedures were performed except for the absence of the mitomycin C application. Silicone tubes were removed at 6 months after surgeries in all patients.

To evaluate the long term results of both groups, we documented the subjective symptoms and classified them as symptom free (no tearing), improvement, and no improvement in tearing by asking patients about the tearing condition at 10 months' follow up after operation. In addition, two objective findings such as the height of tear meniscus and patency of irrigation were documented at the same time (Table 1). We measured the height of tear meniscus mixed with a fixed amount of fluorescein stain ( $5 \mu$ l fluorescein by using micropipette) under cobalt blue light at slit lamp for each patient, and graded it as high tear meniscus $(\geqslant 0.2 \mathrm{~mm})$, moderate tear meniscus $(0.1 \mathrm{~mm}<<0.2 \mathrm{~mm})$, and normal tear meniscus $(\leqslant 0.1 \mathrm{~mm})$. All the examinations were done by the same physician with double blind control. If non-patency was noted, transnasal endoscopy was used to verify the area of obstruction. A $\chi^{2}$ with Yates's correction was used to compare the results of subjective symptoms and objective findings after DCR surgeries for both groups.

\section{Results}

There were 88 DCR surgeries in this study; 44 eyes were in the mitomycin $\mathrm{C}$ group and the remaining 44 eyes were in the conventional group. There was no significant difference in age between the two groups $(p>0.1)$. All patients except two in the mitomycin group remained symptom free (42 eyes) after 10 months' follow up. The satisfaction rate in the mitomycin C group was $95.5 \%$ (42/44). While in the conventional group there were five eyes with excessive tearing after DCR surgery, 31 eyes remained symptom free (no tearing), and eight eyes improved. There was a significant difference between the two groups ( $p<0.05$ ).

As far as the objective findings was concerned, there were two eye samples in the mitomycin $\mathrm{C}$ group classified as having a high

Table 1 Evaluation of the results of DCR surgery

\begin{tabular}{|c|c|c|}
\hline \multicolumn{3}{|l|}{1 Subjective symptoms: } \\
\hline $\begin{array}{l}\text { Symptom free } \\
2 \text { Objective findings: }\end{array}$ & Improvement & No improvement \\
\hline $\begin{array}{l}\text { (A) Height of tear meniscus: } \\
\text { Normal }(\leqslant 0.1 \mathrm{~mm}) \\
\text { (B) Irrigation: }\end{array}$ & Moderate $(0.1 \mathrm{~mm}<<0.2 \mathrm{~mm})$ & High $(\geqslant 0.2 \mathrm{~mm})$ \\
\hline Patent & Non-patent & \\
\hline
\end{tabular}

tear meniscus. One eye sample was classified as having moderate and 41 eye samples as having normal tear meniscus levels. In the conventional group, five eye samples were classified as having a high tear meniscus, seven eye samples as a moderate tear meniscus, and 32 eye samples as a normal tear meniscus. The objective findings of tear meniscus height showed a significant difference between the two groups $(\mathrm{p}<0.05)$.

In the mitomycin $\mathrm{C}$ group, all eyes except two showed patency of the lacrimal drainage system; while in the conventional group five eyes revealed non-patency of the drainage system. Transnasal endoscopic findings in these seven eyes (two in the mitomycin group and five in the conventional group) showed either total septo-osteotomy adhesion or complete obstruction of the osteotomy area, revealing that fibrous tissue growth, scarring, or granulation tissue formation had been noted at the osteotomy area. The patency rate of the lacrimal drainage system in the mitomycin $\mathrm{C}$ group was $95.5 \%$, and that in the conventional group was $88.6 \%$.

During the follow up period, no complications such as abnormal nasal bleeding, mucosal necrosis, or infection were noted in any patients. One patient showed delayed wound healing. Wound disruption was noted during skin suture removal about 7 days after surgery; it may be the result of accidental contact of mitomycin C soaked sponge on the skin wound and could have been prevented by carefully managing the sponge. Fortunately, the wound healed within 2-3 weeks after DCR surgery leaving a barely visible scar with a successful result.

\section{Discussion}

Dacryocystorhinostomy has been accepted as a highly successful procedure in dealing with epiphora from nasolacrimal duct obstruction. A review of the literature reveals an average failure rate of $9.4 \% .^{1-3}$ Failure is generally defined as having symptoms of excessive tearing with the inability to irrigate. McPherson and Egelston noted that three out of seven patients in their study who underwent a second operation were found to have dense scar tissue present at the osteotomy site. ${ }^{10}$ Pico stated that "in every instance, the cause of failure was found at the secondary surgery to be an obstruction of the new drainage channel by an occluding membrane, which on histologic examination was shown to be composed of organised granulation tissue." ${ }^{11}$ Allen and Berlin in 1989 reported 20 failed DCRs with the postoperative obstruction distal to common canaliculus. In their study, there were 13 cases with cicatrical closure of the rhinostomy with granulation tissue and three cases with scarring of the osteotomy to the turbinate or septum. ${ }^{4}$ McLachlan et al, on the other hand, proposed the higher incidence of common canalicular obstructions as a cause of DCR failures. ${ }^{6}$

From the literature described above, we see that fibrous tissue growth, scarring, and granulation tissue formation during the healing process will decrease or compromise the 
created surface area of the osteotomy site, leading to surgical failure. The same healing process will also promote adhesion of the osteotomy to the turbinate and septum, or induce obstruction of the common canaliculus. Linberg et al showed that an appropriately large osteotomy made during surgery can narrow down to a final size of approximately $2 \mathrm{~mm}$ due to tissue growth and scarring. ${ }^{12}$ Thus, if we can reduce fibrous proliferation at the osteotomy site and at the anastomosed flaps, the success rate of DCRs may become much higher.

We know that mitomycin C, an anticancer agent isolated from Streptomyces caespitosus, has the ability to significantly suppress fibrosis and vascular ingrowth after exposure to the filtration site of the trabeculectomy for glaucoma. ${ }^{1314}$ The effect of mitomycin $\mathrm{C}$ in glaucoma filtering surgery has been widely discussed and proved to be effective in reducing intraocular pressure. ${ }^{815}$ In DCR surgery, we tried to use mitomycin $\mathrm{C}$ soaking over the osteotomy site and the anastomosed flaps to suppress fibrous proliferation and scar formation. Theoretically, this modification should reduce the fibrous adhesion between the osteotomy site and the nasal septum as well as inhibit scarring around the opening of the common canaliculus. Thus, mitomycin $\mathrm{C}$ should prevent further shrinkage of the final surface area of the osteotomy and prevent the obstruction of the common canaliculus opening.

In our previous study, the mean actual osteotomy size in mitomycin $\mathrm{C}$ group shrank from $66.28 \mathrm{~mm}^{2}(100 \%)$ initially to $27.10 \mathrm{~mm}^{2}$ $(40.89 \%) 6$ months after DCR surgery. On the other hand, the mean actual osteotomy size in control group shrank from $65.55 \mathrm{~mm}^{2}(100 \%)$ initially to $10.83 \mathrm{~mm}^{2}(16.52 \%) 6$ months after DCR surgery. ${ }^{9}$ It is concluded that application of the mitomycin $\mathrm{C}$ over the osteotomy site is effective in maintaining a larger osteotomy site. Ugurbas et al studied the histopathological effects of mitomycin C on transnasal DCR by using $0.5 \mathrm{mg} / \mathrm{ml}$ mitomycin $\mathrm{C}$ and soaking for $2 \frac{1 / 2}{2}$ minutes over the osteotomy site. The light and electron microscopy showed attenuated epithelium as well as looser and hypocellular subepithelial connective tissue on mitomycin C soaking specimens. They concluded that mitomycin $\mathrm{C}$ soaking can result in a decrease in density and cellularity of mucosa, and hence, enhance the success of DCR surgery. ${ }^{16}$ Yeatts and Neves reported eight cases of repeat DCR using mitomycin $\mathrm{C}$ soaking with successful results. ${ }^{17}$ They recommended that the adjunctive use of mitomycin $\mathrm{C}$ may increase the success rate of repeat DCR.

In this study, there were 42 eyes totally free from epiphora in the mitomycin $\mathrm{C}$ group after 10 months' follow up. Only two out of 44 eyes $(4.5 \%)$ failed to response to DCR surgery. While in the conventional group five out of 44 eyes $(11.4 \%)$ were reported to be unsatisfactory with the results of DCR surgery; 31 eyes were free from epiphora and eight eyes reported to be improved in this group. There was a significant difference between the two groups according to the subjective symptoms reported by patients.
The height of the tear meniscus was also measured and compared between the mitomycin and conventional groups. Forty one eyes in the mitomycin $\mathrm{C}$ group were classified to have a normal tear meniscus and one eye to have a moderate tear meniscus compared with 32 eyes in the conventional group to have a normal and seven eyes to have a moderate tear meniscus. Also, there were five eyes in the conventional group classified to have a high tear meniscus compared with two eyes in the mitomycin C group. This was also significant.

As for the patency of the lacrimal drainage system and transnasal endoscopic findings, we found that two eyes in the mitomycin $\mathrm{C}$ group showed non-patency of the lacrimal drainage system when irrigated, and an obstruction over the osteotomy area. In the conventional group, there were five eyes reported to be non-patent with obstruction over the osteotomy site diagnosed by irrigation as well as transnasal endoscopy. The patency rate of the lacrimal drainage system after DCR surgery was $95.5 \%$ in the mitomycin $\mathrm{C}$ group compared with $88.6 \%$ in the conventional group.

From the results described above, it seems reasonable to conclude that intraoperative mitomycin C application can improve the satisfaction rate and the success rate of DCR surgery.

Many complications due to a mitomycin C application have been reported in both pterygium and glaucoma filtration operations. Severe secondary glaucoma, corneal perforation, corectopia, secondary cataract, and scleral calcification are documented as complications in using topical mitomycin $\mathrm{C}$ as a medical adjunct to pterygium surgery. ${ }^{18}$ Hypotony related maculopathy, infection, and endophthalmitis have been found in patients undergoing glaucoma filtration surgery after exposure to mitomycin C. ${ }^{10}{ }^{19}$ Fortunately, in our study, there were no complications such as abnormal nasal bleeding, mucosal necrosis, or infection noted with mitomycin C soaking. Only one case initially presented with delayed wound healing which may have been due to accidental contact of mitomycin $\mathrm{C}$ soaked sponge on the skin wound. The wound healed within 2-3 weeks after DCR surgery leaving a barely visible scar and with a successful result.

In summary, although a high success rate of external DCR surgery has been reported, 10\% of cases still fail. In our experience, DCR with intraoperative mitomycin C soaking over the osteotomy and anastomosed flaps can minimise the adhesions around the septoosteotomy area as well as the opening of the common canaliculus. In this way, mitomycin C soaking during DCR surgery is a useful modified procedure to improve the success rate of external DCR. Recently, new reports have shown that endonasal laser assisted DCR can be an alternative to conventional external $\mathrm{DCR}^{20-22}$; maybe it will be helpful to apply mitomycin C over a laser created osteotomy site to increase the success rate of laser assisted DCR and revised DCR surgery. 
The authors have no proprietary interest in the development or marketing of any materials mentioned here.

1 Tarbet KJ, Custer PL. External dacryocystorhinostomy: surgical success, patient satisfaction, and economic cost. surgical success, patient satisfaction,
Ophthalmology 1995;102:1065-70.

2 Walland MJ, Rose GE. Factors affecting the success rate of open lacrimal surgery. Br f Ophthalmol 1994;78:888-91. Becker BB. Dacryocystorhinostomy without flaps. Ophthalmic Surg 1988;19:419-27.

4 Allen K, Berlin AJ. Dacryocystorhinostomy failure: association with nasolacrimal silicone intubation. Ophthalmic Surg 1989;20:486-9.

5 Rosen N, Sharir M, Moverman DC, et al. Dacryocystorhinostomy with silicone tubes: evaluation of 253 cases. $O p h-$ thalmic Surg 1989;20:115-9.

6 McLachlan DL, Shannon GM, Flanagan JC. Results of dacryocystorhinostomy: analysis of the reoperations. $\mathrm{Oph}$ thalmic Surg 1980;11:427-30.

7 Singh G, Wilson MR, Foster CS. Mitomycin eye drops as treatment for pterygium. Ophthalmology 1988;95:813-21.

8 Cano-parra J, Diaz-Llopis M, Maldonado MJ, et al. Prospective trial of intraoperative mitomycin $\mathrm{C}$ in the treatment of primary pterygium. Br f Ophthalmol 1995;79:439-41.

primary pterygium. Brf Ophthalmol 1995;79:439-41.
9 Kao SCS, Liao CL, Tseng JHS, et al. Dacryocystorhinostomy with intraoperative mitomycin C. Ophthalmology tomy with intraop

10 McPherson SD, Egelston D. Dacryocystorhinostomy: a review of 106 operations. Am $\mathcal{f}$ Ophthalmol 1959;47:328-31. 11 Pico G. A modified technique of external dacryocystorhinostomy. Am $\mathcal{F}$ Ophthalmol 1971;72:679-90.

12 Linberg JV, Anderson RL, Bumsted RM, et al. Study of intranasal ostium external darcryocystorhinostomy. Arch Ophthalmol 1982;100:1758-62.
13 Megevand GS, Salmon JF, Scholtz RP, et al. The effect of reducing the exposure time of mitomycin $\mathrm{C}$ in glaucoma filtering surgery. Ophthalmology 1995;102:84-90.

14 Lee DA, Lee TC, Cortes AE, et al. Effects of mithramycin, mitomycin, daunorubicin, and bleomycin on human subconjunctival fibroblast attachment and proliferation. Invest Ophthalmol Vis Sci 1990;31:2136-44.

15 Bergstrom TJ, Wilkinson WS, Skuta GL, et al. The effects of subconjunctival mitomycin-C on glaucoma filtration surgery in rabbits. Arch Ophthalmol 1991;109:1725-30.

16 Ugurbas SH, Zilelioglu G, Sargon MF, et al. Histopathologic effects of mitomycin C on endoscopic transnasal dacryocystorhinostomy. Ophthalmic Surg Lasers 1997;28: $300-4$.

17 Yeatts RP, Neves RB. Use of mitomycin C in repeat dacryocystorhinostomy. Ophthalmic Plast Reconstruct Surg 1999; 15:19-22.

18 Rubinfeld RS, Pfister RR, Stein RM, et al. Serious complications of topical mitomycin-C after pterygium surgery. Ophthalmology 1992;99:1647-54.

19 Kupin TH, Juzych MS, Shin DH, et al. Adjunctive mitomycin $\mathrm{C}$ in primary trabeculectomy in phakic eyes. Am $\mathcal{f} O p h-$ thalmol 1995;119:30-9.

20 Massaro BM, Gonnering RS, Harris GJ. Endonasal laser dacryocystorhinostomy: a new approach to nasolacrimal duct obstruction. Arch Ophthalmol 1990;108:1172-6.

21 Boush GA, Lemke BN, Dortzbach RK. Results of endonasal laser-assisted dacryocystorhinostomy. Ophthalmology 1994;101:955-9.

22 Kong YT, Kim TI, Kong BW. A report of 131 cases of endoscopic laser lacrimal surgery. Ophthalmology 1994;101: 1793-800. 